\title{
EL PUESTO DEL GOBERNANTE EN EL COSMOS Y SUS RITOS DE PODER
}

\section{Mercedes de la Garza Camino}

Centro de Estudios Mayas. Instituto de Investigaciones Filołógicas Universidad Nacional Autónoma de México

\begin{abstract}
During the Classic period the Maya ruler was considered as a sacred being. This condition was acquited through diferent rites beginning with the access to the trone, as is depicted in plastic representations of the rulers, and several references on the matter were recorded in colonial documents. Also, there were specific simbols and emblems representatives of his power.

ResUMEn: En este trabajo se destaca la figura del gobernante maya del periodo Clásico como un ser sagrado, condición que se adquiria a través de diversos ritos al acceder al poder. Este carácter sagrado resulta evidente en las representaciones plásticas de los gobernantes, y se encuentran referencias al respecto en diversas fuentes coloniales. Asimismo, se mencionan algunos de sus principales símbolos y emblemas de poder.
\end{abstract}

El que es consagrado se une a los dioses y se convierte en uno de ellos (Satapatha Brahmana, III, 1, 1, 8).

Hablar de los "ritos de poder" implica que en el mundo maya el gobernante fue considerado como un ser sagrado, pero al parecer no por el mero hecho de ser hijo de gobernante o miembro de un linaje ilustre, como ocurrió en otras culturas antiguas, sino que debía adquirir esta condición al tomar el poder a través de diversos ritos. Múltiples símbolos en las representaciones de los gobernantes del periodo Clásico, así como referencias de las fuentes escritas coloniales, nos revelan el carácter sagrado del gobernante $y$ algunos datos sobre esos ritos, que incluian, tanto el acceso al poder, como los que después habitualmente practicaban los grandes señores.

Desde $1982^{1}$ destaqué los ritos iniciáticos de los gobernantes mayas clásicos y su carácter de hombres supe- riores con poderes sobrenaturales, con base en un análisis comparativo de las distintas fuentes. Las principales figuras humanas esculpidas y pintadas en el arte plástico del periodo Clásico habían sido ya identificadas como personajes reales, como gobernantes-sacerdotes, hacía muchos años, aunque no se habian hallado sus glifos nominales, ni se hablaba de la historia de sus hazañas, ya que no se pensaba en inscripciones de tipo histórico. Fueron las investigaciones de la epigrafista Tatiana Proskouriakoff, a partir de 1960, las que abrieron ese camino de investigación epigráfica, muy cultivado hoy día.

Además de los ritos iniciáticos, en otros trabajos he señalado la identificación del gobernante con el Sol, como "Corazón del cielo", eje o centro del mundo, y su significación de motor del cosmos. ${ }^{2}$ Ahora, recogiendo esas interpretaciones, $y$ a la luz de nuevos datos $y$ de la significación universal del gobernante o rey, puedo

'El universo sagrado de la serpiente entre los mayas. México, UNAM, IIFL, CEM, 1982.

${ }^{2}$ El hombre en el pensamiento religioso nahuatl y maya, México, UNAM, IIFL, CEM, 1975, y "Le forze sacre dell'universo maya", Culture e religioni indigene in America centrale e meridionale, pp. 95-166, al cuidado de Lawrence E. Sullivan, Tratrato di Antropologia del Sacro, volumen 6, Milano, Jaca Book-Massimo, 1997.

Estudios de Cultura Maya. Vol. XXII, 2002

Instituto de Investigaciones Filológicas/

Centro de Estudios Mayas, UNAM

ISSN 0185-2574 
confirmar su carácter sagrado, y destacaré los que considero los principales ritos de poder de los gobernantes mayas, muchos de los cuales tienen un sentido iniciático.

\section{El poder sagrado del gobernante}

La idea del gobernante como un ser sagrado se encuentra en casi todas las culturas antiguas. El gobernante representa al dios supremo en la tierra, y es así mediador entre los dioses y los hombres. Por ese papel, el gobernante está situado en el centro del mundo, en el eje cósmico, que es el sitio donde puede reunir en él mismo la totalidad de las energías divinas para esparcirlas sobre el universo entero. ${ }^{3}$ Es el motor inmóvil del mundo, ya que su virtud irradia desde el centro hacia las cuatro direcciones, y esta función de regulador del universo se extiende del dominio cósmico al dominio social.

Por ese sitio central, en muchos pueblos el rey se ha identificado con el Sol, personificando el orden del cosmos, como ocurre con el faraón egipcio, considerado de la misma naturaleza que $\mathrm{Ra}$, dios supremo; con el inca, como imagen del dios solar Inty, e incluso con el Rey Sol, Luis XIV. Por eso, creían los egipcios que a la muerte del faraón, el caos amenazaba al orden del universo, y sólo el advenimiento de un nuevo faraón renovaba la creación original, restablecía el equilibrio de la naturaleza.

En diversas culturas, otro aspecto del gobernante ligado con el Sol es su carácter guerrero. Él no combate, pero su presencia es necesaria en la guerra; "No se gana una batalla sin rey", dice un aforismo irlandés. ${ }^{4}$ Además, es él quien recibe los tributos y ha de distribuirlos entre la población, pues si no es generoso altera la fecundidad de la tierra, los animales y las plantas. ${ }^{5}$
También se ha considerado que el rey es una proyección del yo superior. Más allá de su significación histórica y cósmica, adquiere valor ético y psicológico. En la psicología profunda, el rey es arquetipo de intuición y sabiduría superiores, y se le atribuyen dones sobrenaturales, como la curación de enfermedades. "El rey es, con el héroe, el santo, el padre, el sabio, el arquetipo de la perfección humana y moviliza las energías espirituales para realizarse". ${ }^{6}$ Por eso, el rey debe hallarse en la plenitud de la vitalidad y no puede manifestar síntomas de envejecimiento; si ello sucede, debe someterse a la autoinmolación o al regicidio.?

Muchas de estas significaciones universales se encuentran entre los mayas. La idea cosmológica de los tres niveles cósmicos y de los cinco rumbos del universo, que rigen el espacio y el tiempo, provienen del movimiento del Sol, tanto del ciclo diario como del anual, que determina los puntos cardinales. Los equinoccios y los solsticios fueron momentos esenciales para la vida del maya, porque en ellos se generaban energías sagradas extraordinarias. Por eso considero que el Sol fue el dios supremo del panteón maya, identificado con la energía sagrada del cielo. El Sol es Itzamná Kinich Ahau, "Señor Dragón del ojo solar", como le llamaban los mayas yucatecos, que representa al Sol en el cenit, cuando toca el extremo superior del axis mundi, en la cúspide de la pirámide celeste, y su opuesto en el mundo inferior fue el Sol jaguar o el Sol muerto, cuyo punto extremo es el nadir, en la punta de la pirámide invertida del inframundo.

El mundo del hombre es para los mayas un microcosmos que repite el ordenamiento cósmico y se inserta en él. En el mundo humano se da la reiteración ritual del cosmos, en sus cuatro rumbos y en su centro. Éste se representa con diversos símbolos: la montaña sagrada (simbolizada a su vez por la pirámide, la cual también

\footnotetext{
${ }^{3}$ Gérard de Champeaux y Dom Sébastien Sterckx, Introducción a los simbolos. Madrid, Ediciones Encuentro, 1989, p. 449.

${ }^{4}$ Jean Chevalier y Alain Gheerbrant, Diccionario de los simbolos. Barcelona, Editorial Herder, 1991, p. 883.

${ }^{5} \mathrm{Tbidem}$.

${ }^{6}$ Chevalier y Gheerbrant, op. cit., p. 884 .

${ }^{7}$ Hans Biedermann, Diccionario de símbolos. Barcelona-Buenos Aires-México, Editorial Paidós, 1993, p. 395. Estudios de Cultura Maya. Vol. XXII, 2002 
representa al cielo escalonado), el templo (páginas 75 76 del Códice Madrid), el poste ritual (acanté), la ceiba y la escalera, mencionadas ambas en el Libro de Chilam Balam de Chumayel. Pero este centro no es un punto, sino un eje, pues une el inframundo, la tierra y el cielo, por lo que el verdadero centro, el punto primordial, alrededor del cual gira el cosmos, estaría en el centro de la tierra; y ahí, precisamente, está situado el hombre que es el centro del mundo humano: el gobernante, como manifestación humana del Sol.

Así lo expresa, como entre muchos ejemplos, la lápida de la tumba del gobernante Uoxoc Ahau o Pacal en Palenque (Fig. 1): el personaje se halla en el centro; sobre él se levanta el axis mundi y los cuatro rumbos, determinados por una cruz, que está constituida por serpientes bicéfalas, símbolo de Itzamná, el dios celeste; en lo alto se posa el pájaro-serpiente, una de las formas plásticas del dios supremo, que por su posición sobre el axis mundi, podemos considerar como epifanía de Itzamná Kinich Ahau, el Sol en el cenit. Y debajo de la figura humana, vemos la cavidad del inframundo formada por huesos, el mascarón del dios de la tierra y la muerte, y el dragón terrestre como serpiente bicéfala descarnada, réplica del dragón celeste. Y para corroborar la idea de que el gobernante es el centro del universo entero, alrededor de la imagen cosmológica se extiende la banda astral, Vía Láctea, cuerpo del dragón celeste. También confirman su carácter de centro y motor del universo el dado y la esfera de jade que el esqueleto de Pacal llevaba en las manos, símbolos cosmológicos universales del espacio cuadrangular y el tiempo circular.

$\mathrm{Y}$ además, la identificación de este gobernante particular con el Sol se manifiesta en el hecho (descubierto por Linda Schele) de que en el solsticio de invierno, visto desde la torre del Palacio, el Sol se pone exactamente en el centro del Templo de las Inscripciones, como para mostrar que el gobernante ahí enterrado descendió al inframundo como el astro. Por eso, a su tumba se accede desde el templo, descendiendo los nueve estratos de la pirámide, que simbolizan los del mundo infraterrestre.
En varias otras imágenes plásticas el gobernante surge de las fauces del monstruo terrestre, como en el gran monolito de Quiriguá, conocido como zoomorfo $P$, lo que muestra también claramente su equiparación con el Sol.

Coincidimos, así, con Claude Baudez, quien analizando el simbolismo del friso de los cuatro reyes de Balamkú, dice:

El ciclo dinástico es equiparado al ciclo solar. En esta concepción, el acceso al trono es ilustrado por el rey saliendo de las fauces del monstruo terrestre, como el Sol sale de la boca de la Tierra; la muerte del rey es vista como una puesta de Sol, cuando cae en la boca

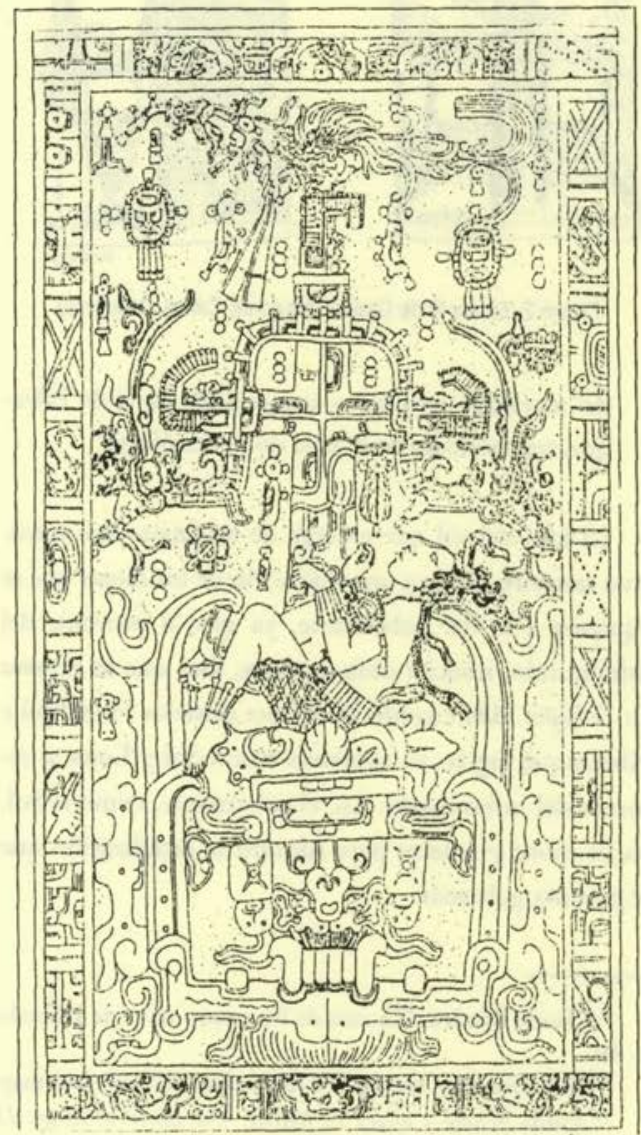

Figura 1. Lápida de la tumba del Templo de las Inscripciones, Palenque (dibujo de Agustin Villagra). 


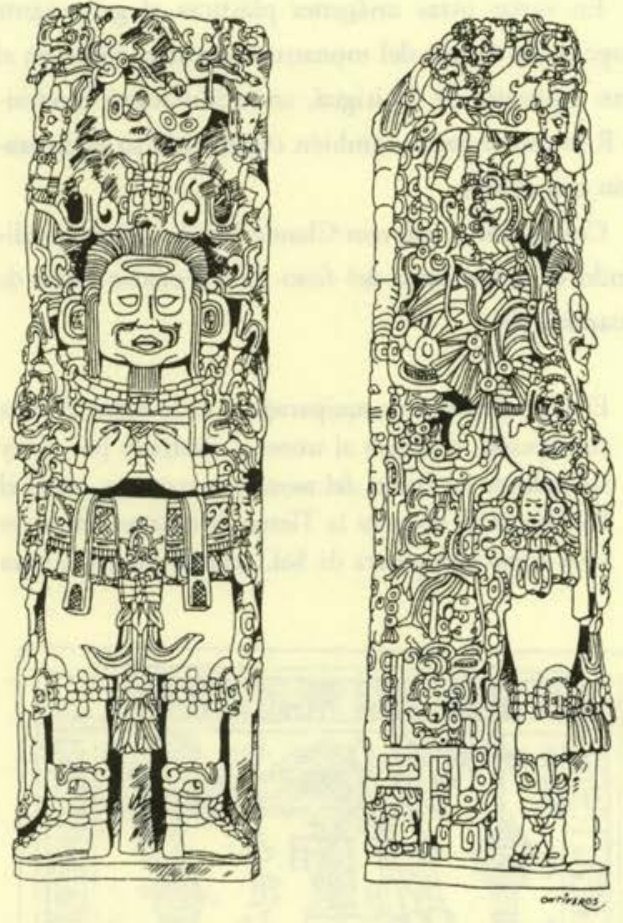

Figura 2. Estela D de Copán (dibujo de Carlos Ontiveros).

del monstruo terrestre - como el rey Pacal de Palenque, representado en la tapa de su sarcófago. ${ }^{8}$

$\mathrm{La}$ idea del sol que emerge de las fauces del monstruo terrestre, alude a una iniciación de los dioses que se equipara a la del gobernante, ya que al provenir del inframundo, resucita cada mañana, idea que se expresa en el Popol Vuh, cuando los héroes gemelos Hunahpú e Ixbalanqué logran su apoteosis como Sol y Luna al retornar del inframundo. Así, el gobernante, como el Sol, ha de morir y renacer para adquirir la sacralización que le permita gobernar.
"El gobernante es el Sol del mundo humano"; Corazón del mundo social, equivalente a la deidad creadora denominada Corazón del Cielo en el Popol Vuh, título que alude claramente al Sol como axis mundi. Las epigrafistas Schele y Miller afirman que los gobernantes se llamaban mah kina, "gran señor Sol" o ahau, señor, lo cual corrobora la identificación del gobernante con el Sol como eje del mundo. ${ }^{10}$

Otras veces, el gobernante está de pie sobre el monstruo de la tierra, como en la estela 2 de Bonampak. Esta posición es la de intermediario entre el Cielo y la Tierra, como el mediador, el demiurgo cósmico.

En diversos pueblos, el rey era a la vez sumo sacerdote: las fiestas, sobre todo las del Año Nuevo, eran oficiadas por él. Del mismo modo, en el mundo maya las grandes fiestas comunitarias debieron haber sido oficiadas por el gobernante, fungiendo como sumo sacerdote, como aquel que permite la comunicación entre los hombres y los dioses. ${ }^{11}$

Los principales emblemas de poder de los gobernantes, como en muchas partes del mundo, tenían la función de expresar a la comunidad su sacralidad y su sitio en el cosmos. Estos emblemas son los bastones de mando, el cetro, el trono y el tocado o la corona.

Entre los mayas, el símbolo más común del gobernante es el dragón, forma principal del dios supremo (con sus rasgos celestes, solares, acuáticos y relacionados con sangre y maíz, cuyos nombres yucatecos son Itzamná, Kinich Ahau, Chaac y Bolon Dz'acab o Kawil). En la mayoría de los retratos de los gobernantes clásicos, el personaje porta el dragón celeste sobre su pecho, en forma de serpiente bicéfala, como barra ceremonial (Fig. 2); lo lleva en su mano, como bastón ceremonial y como cetro maniquí, y también aparece en su tocado y otros atavíos.

${ }^{8}$ Claude Baudez, "La casa de los cuatro reyes de Balamkú", Arqueologia Mexicana, vol. III, no. 18, México, INAH, 1996, p. 40 .

${ }^{2}$ Mercedes de la Garza, "Le forze sacre dell'universo maya", p. 147.

${ }^{10}$ Linda Schele y Mary E. Miller, The Blood of Kings; Dinasty and Ritual in Maya Art, George Braziller Inc., New York, Kimbell Art Museum, Forth Worth, 1986.

11 Ver Mircea Eliade, Historia de las creencias y de las ideas religiosas, 4 vols. Madrid, Ediciones Cristiandad; vol. I, 1978, p. 159.

Estudios de Cultura Maya. Vol. XXII, 2002

Instituto de Investigaciones Filológicas/

Centro de Estudios Mayas, UNAM 


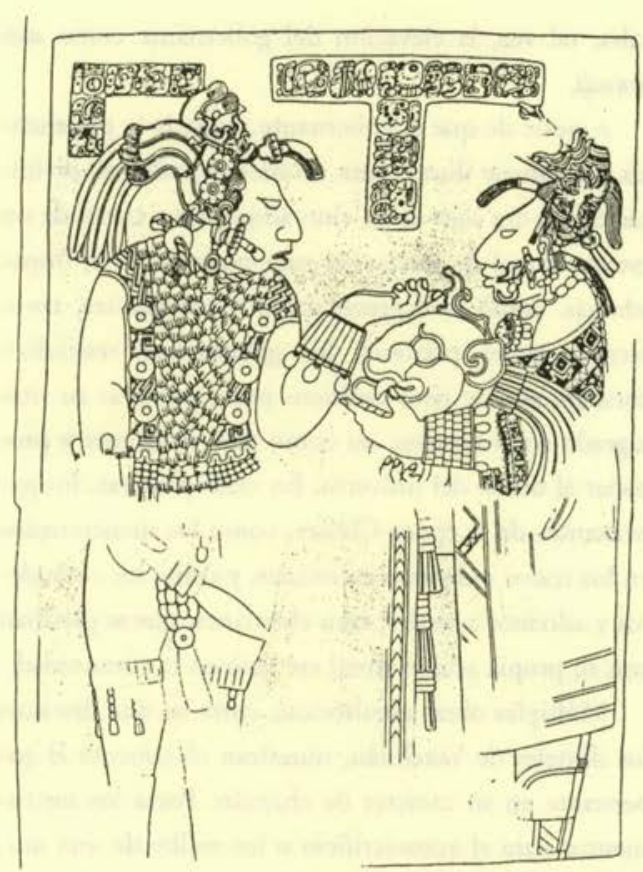

Figura 3. Dintel 26 de Yaxchilán (Graham 1977).

El dragón simboliza, de este modo, la omnipotencia del gobernante, el cual se representa a veces con rasgos del propio dragón en el rostro, para mostrar su vínculo con la deidad suprema.

Además, el Ahau porta en diversas formas la figura del jaguar, con el que se identifica por representar éste al Sol del inframundo y una de las energías sagradas más fuertes de la naturaleza, y por ser, asimismo, el principal alter ego zoomorfo de los hombres de poder. Lo vemos en sus atavíos; en su mano, a manera de cetro, como en las estelas 3 y 5 de Xultún; como bulto ofrecido por una mujer, como en el dintel 26 de Yaxchilán (Fig. 3); en los tronos y en otras formas. A veces, el mandatario se representa transmutado en jaguar, como en Kabah. En algunos códices de otros sitios de Mesoamérica, por ejemplo el Códice Porfirio Díaz de Oaxaca, se ve al gobernante acompañado por un jaguar sedente que representa su nahual. ${ }^{12}$ Todo ello confirma la sacralización del gobernante y el hecho evidente de que el poder no era solamente político o guerrero, sino que implicaba el vínculo con lo sagrado, como en todos los pueblos religiosos.

El cetro es, a nivel universal, un modelo reducido del bastón de mando, símbolo vertical que representa primero al hombre y después al hombre poderoso y el poder recibido de los dioses. ${ }^{13}$ Asimismo, el cetro puede representar el axis mundi y los cuatro sectores cósmicos, lo cual es muy claro en los dinteles 2 y 5 de Yaxchilán, en forma de cruz, sobre cuya parte superior se ve al ave sagrada, símbolo universal de la ascensión al cielo, de la soberanía (Fig. 4). En el caso de los mayas esta ave es un quetzal.

En cuanto al tocado, que equivale a la corona en otros pueblos, él sitúa al gobernante en relación con todo lo que le rodea, simbolizando también el punto central del cosmos. Ambos atributos de poder resumen el significado axial del rey. El pectoral, las oreje-

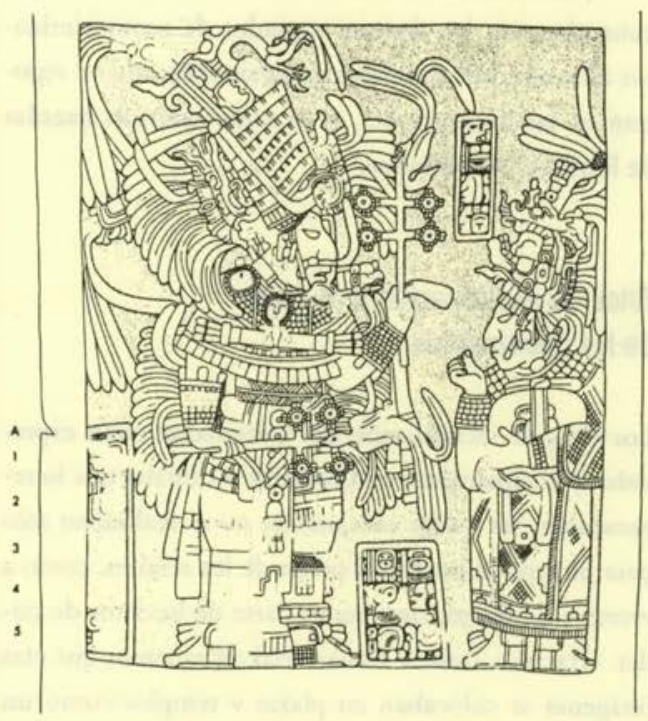

Figura 4. Dintel 5 de Yaxchilán (Graham 1977).

\footnotetext{
12 Códice Porfirio Diaz, en Antigüedades mexicanas publicadas por la Junta Colombina de México en el cuarto centenario del descubrimiento de América. México, Oficinas Tipográficas de la Secretaría de Fomento, 1892, lám. 2 anv.

${ }^{13}$ Champeaux y Sterckx, op. cit., p. 451.
} 
ras, el cinturón, el ex o braguero, las ajorcas, las sandalias, así como las lanzas constituyen asimismo símbolos del poder del gobernante, que aluden a sus distintas funciones.

El trono, que muchas veces es un ser bicéfalo, serpentino felino, manifiesta que la deidad suprema sostiene al soberano en la forma de esas epifanías animales. Es símbolo de que el señor que se sienta en él representa al cosmos íntegro. Y por sí solo, el trono es sagrado, pues alude a la presencia del señor. El trono es una eminencia, está elevado, como la montaña cósmica, por lo que es también un eje del mundo. En relación con todos estos elementos del gobernante, como dicen Champeaux y Sterckx, "las civilizaciones más diversas atestiguan con una continuidad notable las mismas concepciones fundamentales". ${ }^{14}$

Las representaciones de los gobernantes mayas se acompañan de registros escritos de sus biografías con los acontecimientos más destacados de su gobierno, como ha mostrado la epigrafía. Muchos de esos hechos pueden considerarse como divinos, en tanto que coinciden con los tiempos sagrados de acontecimientos astronómicos o míticos excepcionales, que se registran en las inscripciones, $y$ en tanto que son hazañas de hombres sacralizados.

\section{Ritos de sacralización y de poder de los gobernantes}

Los ritos de sacralización del gobernante están expresados principalmente en las estelas y dinteles que lo representan, los cuales obviamente no se realizaban sólo para mostrar al pueblo el poder de los señores, como a veces se ha dicho, sino como parte de los ritos de poder. Gracias a Tatiana Proskouriakoff sabemos que esas imágenes se colocaban en plazas y templos como un episodio de la ceremonia de entronización que signifi- caba, tal vez, la elevación del gobernante como axis mundi.

A pesar de que el gobernante requería la pertenencia a un linaje ilustre para acceder al poder, su divinización no era algo dado, sino adquirido a través de un estricto ritual de iniciación para poder subir al trono; además, como lo expresan las diversas fuentes, tanto escritas como plásticas, los gobernantes realizaban constantemente ritos ascéticos para conservar su sitio sagrado en el cosmos, así como para mantener y propiciar el orden del universo. En otras palabras, los gobernantes de la época Clásica, como los mencionados en los textos indígenas coloniales, y como los curanderos $y$ adivinos actuales, eran chamanes, que se ganaban con su propia acción ritual ese sitio en la comunidad.

Múltiples obras escultóricas, entre las que destacan los dinteles de Yaxchilán, muestran claramente al gobernante en su carácter de chamán. Porta los instrumentos para el autosacrificio o los recibe de una mujer, y ésta le presenta otras veces el bulto sagrado de la parafernalia chamánica, denominado pizom gagal en el Popol Vuh, como símbolo de poder. Otras veces practica la extracción de sangre y el rito onanista de ofrenda de semen; sostiene la imagen del dios $\mathrm{K}$ o Bolon Dz'acab, que representa, entre otras cosas, la sangre $y$ los autosacrificios, y finalmente, emerge de las fauces de grandes serpientes, lo cual constituía, como veremos, el momento final de su inicialización (Fig. 5).

Los textos indígenas coloniales corroboran el carácter de chamanes que tenían los gobernantes mayas. El Título de Totonicapán llama a los patriarcas Nawal Winak, "hombres naguales", "gente mágica", "los grandes, los sabios", 15 por sus poderes sobrenaturales, ya que el nagual era uno de los principales chamanes en el mundo náhuatl. Los prototipos de estos jefes eran los primeros hombres creados, según el mito cosmogónico: hombres portentosos con poderes sobrenaturales que podían transformarse en animales, sobre

\footnotetext{
${ }^{14}$ Op. cit., p. 457.

${ }^{15}$ El Título de Totonicapán. Ed. facsimilar, transcripción y traducción de Robert M. Carmack y James L. Mondloch, México, UNAM, IIFL, CEM, 1983 (Serie de Fuentes para el Estudio de la Cultura Maya, 3), p. 175.

Estudios de Cultura Maya. Vol. XXII, 2002

Instituto de Investigaciones Filológicas/

Centro de Estudios Mayas, UNAM

ISSN 0185-2574
} 


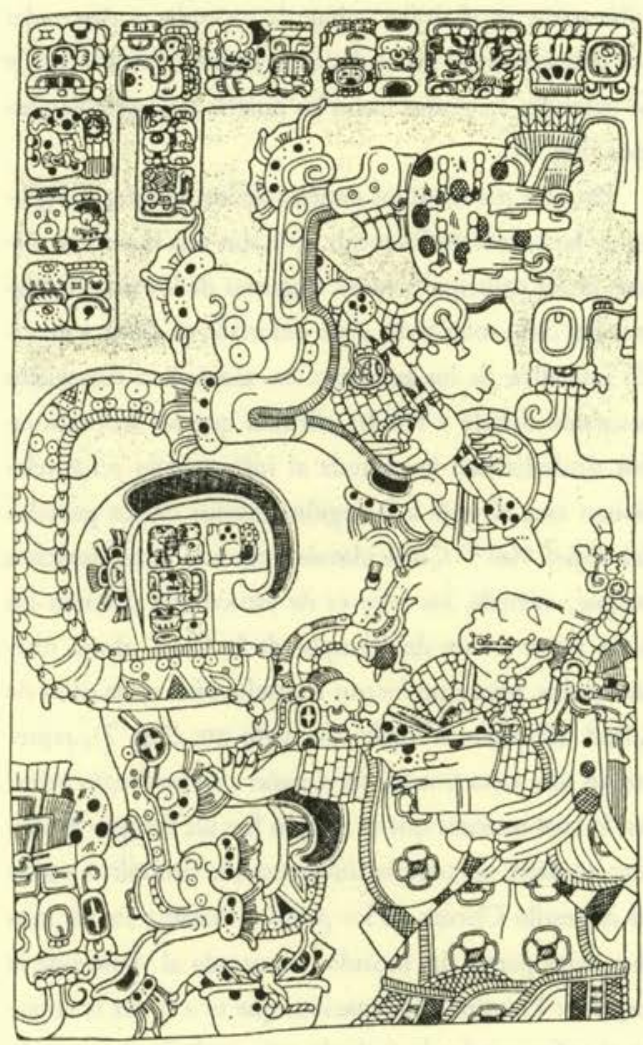

Figura 5. Dintel 25 de Yaxchilán (Graham 1977).

todo en jaguares, $y$ dominar las fuerzas de la naturaleza. Podían llegar al cielo y al inframundo, manejar el rayo y el granizo. ${ }^{16}$ Además, ayunaban, se abstenían de relaciones sexuales, se sacrificaban $y$ adoraban a los dioses. Entre los más notables gobernantes chamanes están: Gucumatz, cuyo nombre es igual al del dios creador; se describe como un rey prodigioso que subía al cielo, bajaba al inframundo, se convertía en serpiente, en águila, en jaguar $y$ hasta en sangre coagulada; ${ }^{17}$ y Tecún Umán, quien se enfrentó a Pedro de Alvarado valiéndose "del arte de los encantos y naguales", o sea, convirtiéndose en águila. ${ }^{18}$

Las fuentes escritas coloniales ${ }^{19}$ mencionan también ciertos ritos de iniciación de esos chamanes que han sobrevivido hasta la actualidad en algunos grupos mayances (mopanes y k'ekchís) y nahuas. En esos ritos, después de un largo aprendizaje, el iniciando va en la noche a un lugar alejado y se coloca cerca de un hormiguero, del cual sale una enorme boa, símbolo de las fuerzas ctónicas; la serpiente lo traga, lo tritura y luego lo expele o lo vomita, ya convertido en un chamán, en un hombre dotado con poderes sobrenaturales, que destacará en su comunidad. Un informante nahua de Tetela del Volcán, donde todavía se practica el rito, afirma que la serpiente traga al iniciando empezando por los pies, de tal modo, que el momento de su muerte se da cuando queda la cabeza dentro de las fauces y el reptil las cierra. Hay cientos de representaciones mesoamericanas con esa imagen del rostro dentro de las fauces, que en nuestra opinión coinciden con ese rito. Éste contiene, además, un símbolo universal: la iniciación a través de ser tragado por un monstruo, uno de cuyos mitos más conocidos es el de Jonás y la ballena.

Las imágenes plásticas del gobernante maya del periodo Clásico, como muchas otras a nivel mesoamericano, revelan que del mismo modo que esos chamanes indígenas actuales, en el mundo prehispánico el hombre destinado a gobernar por su pertenencia a un linaje, pasaba por el rito iniciático de ser tragado por una serpiente, de morir $y$ renacer en el vientre del monstruo, para adquirir el poder de gobernar sobre los otros hombres, para obtener el sitio axial en el mundo humano e identificarse así con el Sol en el cosmos. Y es la serpiente la Maestra de Iniciación en estos

\footnotetext{
${ }^{16}$ Mercedes de la Garza, Sueño y alucinación en el mundo náhuatl y maya. México, UNAM, IIFL, CEM, 1990, p. 135.

${ }_{17}$ Popol Vuh. Las antiguas historias del Quiché, 9a. ed., trad. Adrián Recinos. México, Fondo de Cultura Económica, 1968, p. 90.

18 Titulo de Otzoyá, en Crespo Morales, Mario, Algunos Titulos indigenas del Archivo General del Gobierno del Guatemala. Tesis de Licenciatura en Historia, Universidad de San Carlos de Guatemala, 1968, p. 70-71.

${ }^{19}$ Entre otras, Constituciones Diocesanas del obispado de Chiapa, hechas y ordenadas por su señoria ilustrisima, el señor maestro don fray Francisco Núñez de la Vega, de la orden de predicadores, obispo de Ciudad Real de Chiapa y Soconusco. Ed. María del Carmen León y Mario Humberto Ruz, México, UNAM, IIFL, CEM, 1988 (Fuentes para el Estudio de la Cultura Maya, 6).

Estudios de Cultura Maya. Vol. XXII, 2002

Instituto de Investigaciones Filológicas/

Centro de Estudios Mayas, UNAM 


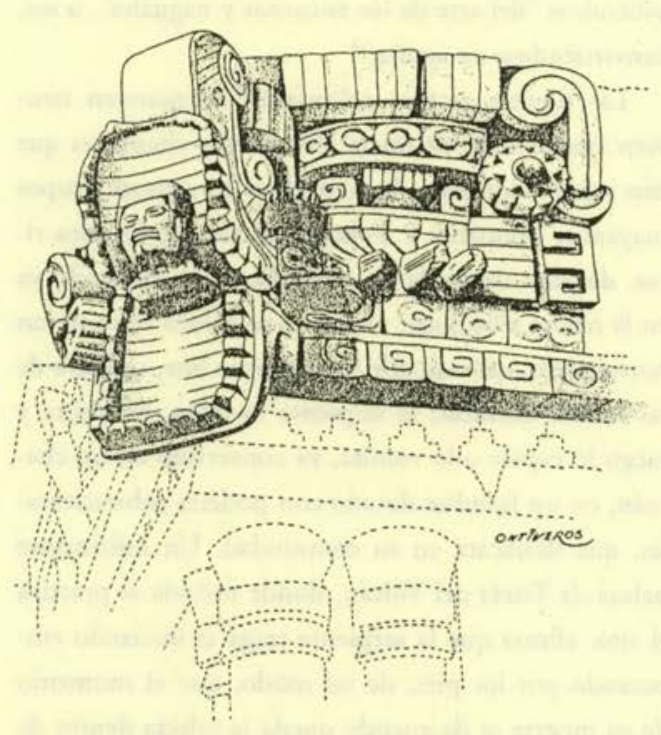

Figura 6. Mascarón del Palacio de Labná (dibujo de Carlos Ontiveros).

ritos porque se trata de un animal ctónico del inframundo, encarnación de la muerte, y la iniciación implica morir; pero también porque es el animal que renace, que abandonando su vieja piel se renueva cíclicamente como la vegetación y como el Sol, y la iniciación culmina en el renacimiento a una vida sacralizada. Por los poderes sobrenaturales así adquiridos, el gobernante es el único capaz de ascender y descender por el axis mundi, hacia el cielo y hacia el inframundo y de extender su poder hacia las cuatro regiones del cosmos (Fig. 6).

Por otra parte, en los paneles de los templos del grupo de las cruces de Palenque, que son una excelente síntesis de las principales ideas religiosas de los mayas, además del ciclo solar y del ciclo del maíz, se alude a un ciclo iniciático de los gobernantes, asociado a esos ciclos naturales. Schele y Freidel afirman que los tres santuarios simbolizaban la entrada al inframundo y los relacionan con el viaje a la región inferior de los gemelos del Popol Vuh. ${ }^{20}$ Coincidimos con esta interpretación porque, además, los relieves de estuco que decoran los frisos norte y este del Templo de la Cruz, ahora muy destruidos, pero que fueron reproducidos en la obra de Alfred Maudslay a finales del siglo xIx (Fig. 7), representan una vista frontal del dragón con las fauces abiertas, lo cual muestra que el templo fue un Templo Monstruo, es decir, un templo iniciático que simbolizó, como los del estilo Chenes de los propios mayas y los de muchas otras partes del mundo, la entrada al vientre de la serpiente Maestra de Iniciación, que es a la vez la entrada al inframundo; la fachada principal de este templo debió haber tenido también fauces serpentinas. Ello confirma los ritos iniciáticos de los gobernantes representados en los paneles.
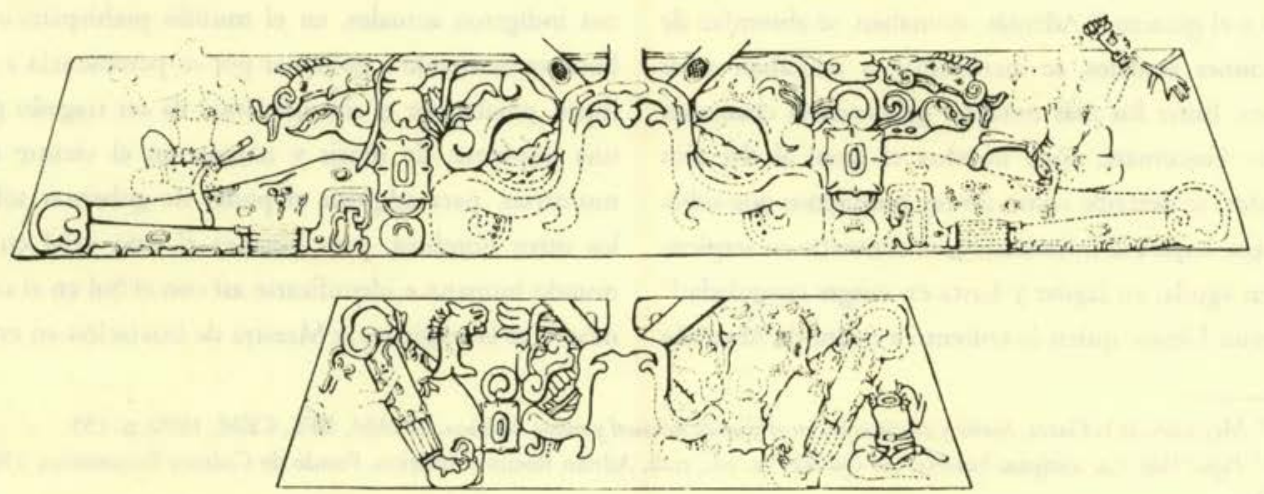

Figura 7. Relieves de estuco que decoraban los frisos norte y este del Templo de la Cruz de Palenque (dibujo de Moisés Aguirre).

${ }^{20}$ Linda Schele y David Freidel, A Forest of Kings. The Untold Story of the Ancient Maya. New York, Quill William Morrow,

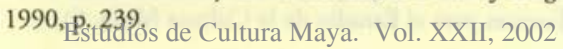

Instituto de Investigaciones Filológicas/

Centro de Estudios Mayas, UNAM 


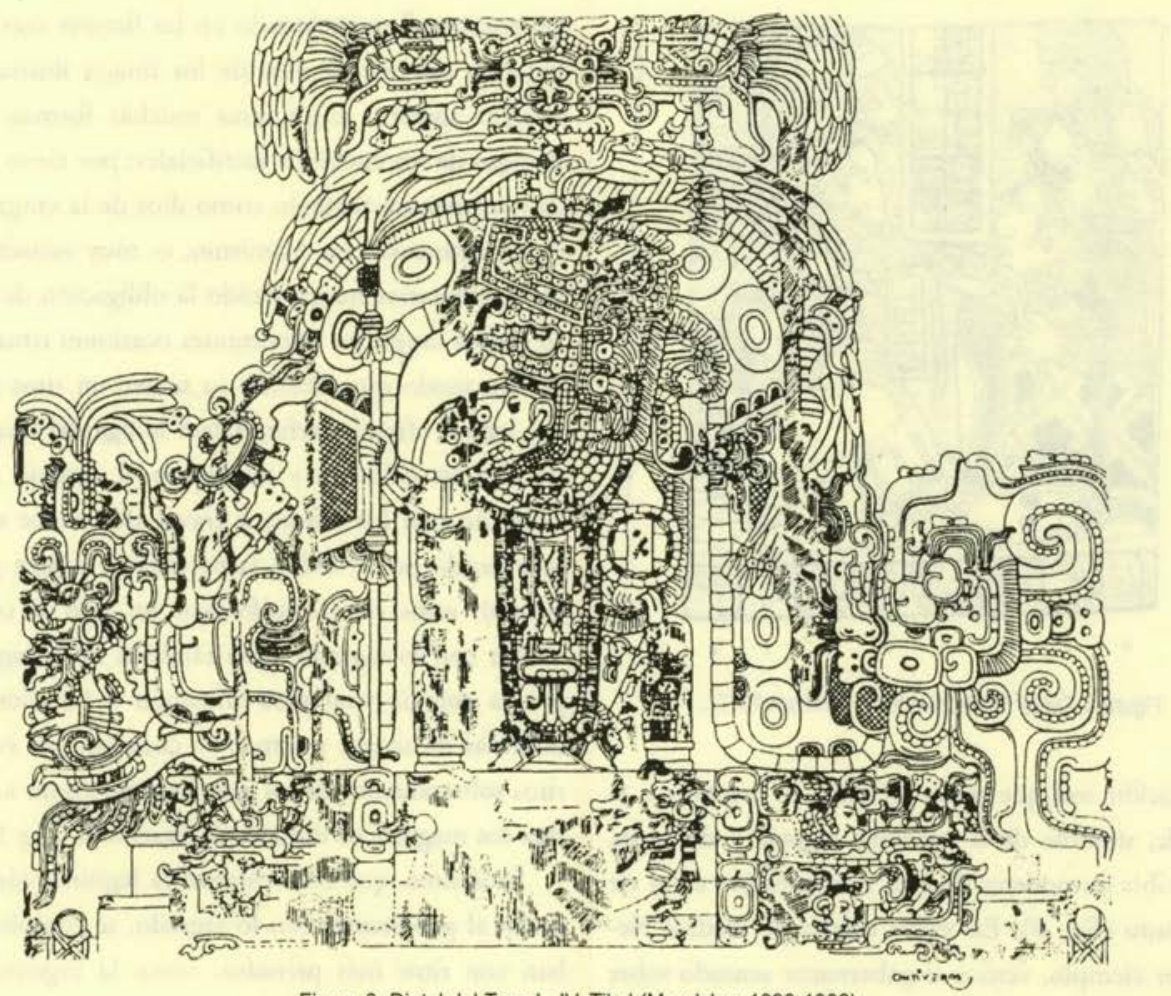

Figura 8. Dintel del Templo IV, Tikal (Maudslay, 1899-1902).

La muerte ritual es condición indispensable para acercarse a los dioses y para obtener una existencia plena en este mundo. La divinización del gobernante no implicaba la desvalorización de la vida humana, sino que por el contrario, precisamente esta condición lograba para toda la sociedad, y aun para la misma naturale$\mathrm{za}$, las bendiciones y la regeneración. ${ }^{21}$

Otro rito muy importante de los gobernantes debió de haber sido el de toma de poder. En muchos pueblos del mundo se proclama al rey elevándolo ya sea sobre el trono $o$, como en Hungría, ascendiendo a un montecillo simbólico, desde donde disparaba cuatro flechas hacia los cuatro horizontes para señalar su dominio sobre los cuatro puntos cardinales. ${ }^{22}$ Ello significa colocarlo en posición de representante del dios en la Tierra. En la India, por ejemplo, cuando el soberano levantaba el brazo se simbolizaba la elevación del axis mundi; cuando se erguía en su trono encarnaba el eje cósmico que se hinca en el ombligo de la tierra. Después avanzaba un paso hacia los cuatro puntos cardinales y subía simbólicamente al cenit. A través de estos ritos, el rey adquiría soberanía sobre las cuatro direcciones del espacio y sobre las estaciones. Dicho de otro modo: adquiría el dominio sobre el universo espacio-temporal. Se trata de una identificación entre muerte y renacimiento rituales y cosmogonía y regeneración del mundo. ${ }^{23}$

Tal vez entre los mayas la toma del poder implicaba un rito de ascenso al trono, acompañado de otro de

${ }^{21}$ Ver Eliade, op. cit., pp. 236-9.

22 Ver Champeaux y Sterckx, op. cit., p. 465.

${ }^{23}$ Eliade, op. cit., p. 238-239. 


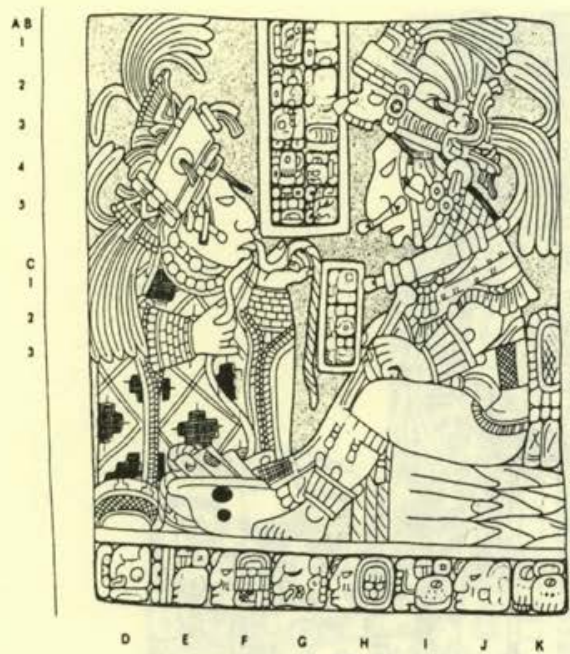

Figura 9. Dintel 17 de Yaxchilán (Graham 1977).

consagración real que pudo consistir en ascender a la pirámide, símbolo de la montaña sagrada y del cielo, para recibir los poderes divinos y constituirse en el eje del mundo (Fig. 8). En varias estelas de Piedras Negras, por ejemplo, vemos al gobernante sentado sobre un trono elevado con huellas de pies que ascienden desde la base; esta imagen fue interpretada por Proskouriakoff precisamente como el ascenso al trono, y la fecha grabada en la estela, como la que registró ese acontecimiento. La ceremonia debió estar precedida por ritos ascéticos de entrada, como ayunos, abstinencias, baños purificatorios y autosacrificios, y debió realizarse cuando el gobernante había ya concluido su principal rito iniciático de sacralización.

$\mathrm{Y}$ debe de haber habido también ritos de renovación del poder del gobernante, ya que los epigrafistas han hallado textos rituales en las inscripciones históricas. ${ }^{24}$ Los mayas identificaron linaje con sangre, lo cual se expresa en el hecho de que el dios más ligado a los gobernantes en los relieves clásicos, el llamado dios $\mathrm{K}$, puede reconocerse como el Bolon Dz'acab, "Nueve generaciones", mencionado en las fuentes escritas coloniales, claramente dios de los linajes ilustres, y su imagen aparece, entre otras muchas formas, en los mangos de los cuchillos sacrificiales; por tanto, la deidad se presenta también como dios de la sangre vertida en autosacrificio. Asimismo, es muy verosímil que los mandatarios hayan tenido la obligación de extraer su propia sangre en importantes ocasiones rituales, del mismo modo que ofrecían su semen en ritos onanistas; ambas ofrendas refrendaban la liga del linaje ilustre con las deidades y renovaban el vínculo del gobernante con los dioses, a través del trance extático (provocado por el dolor, la pérdida de sangre y el orgasmo); estos ritos significaban no sólo la comunicación con lo sagrado, sino también la entrega de la propia energía vital para alimentar a los dioses. Las ofrendas de sangre y semen se cuentan, así, entre los ritos sobresalientes de los gobernantes, como lo muestran los magníficos dinteles de Yaxchilán (Fig. 9).

Esos ritos, que confirmaban la legitimación real y unían al gobernante con lo sagrado, se complementaban con ritos más privados, como la ingestión y la aplicación de psicotrópicos con enemas, conocidos a través de la cerámica (Fig. 10). ${ }^{25}$ Todos esos ritos confirman que los gobernantes eran chamanes, ya que, tanto la ofrenda de sangre como el uso de sustancias psicoactivas formaron parte de los ritos ascéticos para propiciar el éxtasis. Hasta hoy, sólo los chamanes pueden usar, o autorizar el uso de, sustancias que alteran el estado normal de conciencia.

Otro rito muy destacado de los gobernantes del periodo Clásico fue el juego de pelota, cuyo sentido simbólico se revela en los relieves hallados en las canchas, particularmente en los marcadores. Asimismo, los numerosos datos y los mitos contenidos en las fuentes escritas sobre los nahuas acerca del juego de pelota prestan un fuerte apoyo para conocer su significado en toda el área mesoamericana. ${ }^{26}$

\footnotetext{
${ }^{24}$ Schele y Miller, The Blood of Kings, p. 65.
}

${ }^{25}$ Ver Schele y Miller, op. cit.

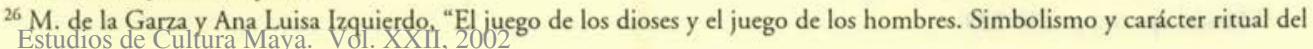
Instituto de Investigaciones Filológicas/ 


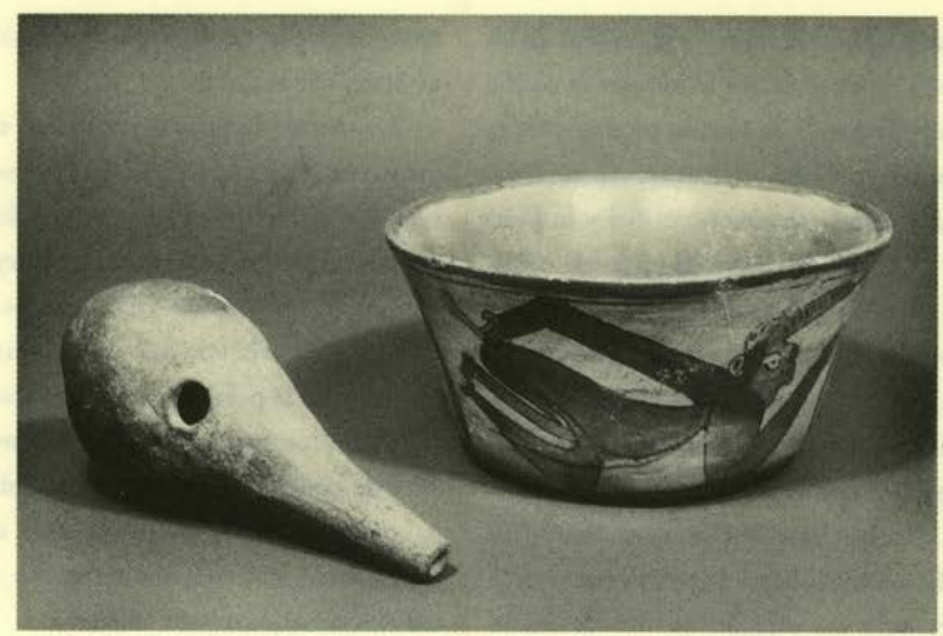

Figura 10. Enema modelado en arcilla procedente de Tlatilco (Preclásico Medio) y vasija policroma maya con la representación de un personaje aplicándose un enema (Clásico Tardio), Museo Nacional de Antropologia (fotografia de José Luis Rojas).

No nos extenderemos en destacar aquí esa significación; baste sólo con recordar que el juego simboliza la pugna entre seres luminosos o celestes y seres oscuros infraterrestres, combate que se da en el campo de juego. El juego, como un rito, significó la reproducción de la lucha de los dioses astrales, como la lucha de contrarios cósmicos, por lo que tal vez en el periodo Clásico el juego tuvo la función ritual de propiciar, por magia simpatética, el movimiento de los astros lo cual equivale a propiciar la existencia de universo.

Los dioses astrales aparecen jugando a la pelota, por ejemplo, en los marcadores de la subestructura de la can-

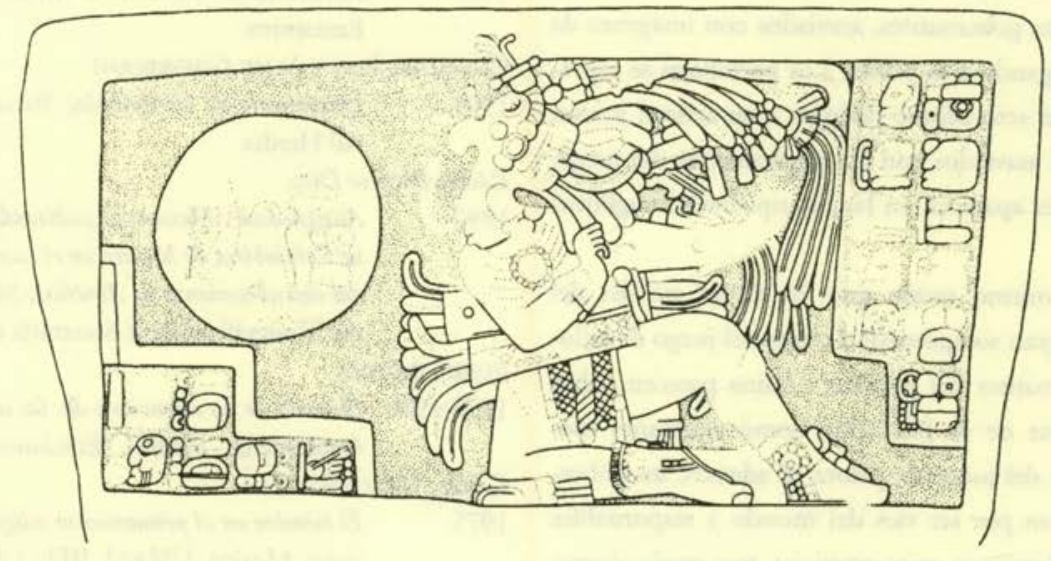

Figura 11. Escalón VI de la Escalinata Jeroglifica No. 2, Templo 33 de Yaxchilán (Graham 1982).

juego de pelota entre los mayas", en El juego de pelota en Mesoamérica, ratces y supervivencias, México, Siglo Veintiuno Editores, 1992.

Estudios de Cultura Maya. Vol. XXII, 2002

Instituto de Investigaciones Filológicas/

Centro de Estudios Mayas, UNAM

ISSN 0185-2574 
cha de Copán realizados en el siglo vi. El análisis de los distintos elementos de estos discos revela que la acción se realiza en el cielo nocturno, momento en el que el Sol está en el inframundo, $\mathrm{y}$ ahí parece haberse representado el episodio iniciático de la aparición del Sol y la Luna en el Popol Vuh, en el que es central el juego de pelota entre los héroes gemelos y los dioses del inframundo. Estos marcadores muestran, así, que en la época Clásica el juego era una explicación mítica del origen y movimiento de los astros, así como de las oposiciones de la naturaleza, y expresan, asimismo, la continuidad de esa creencia hasta la época en que se escribió el Popol Vuh.

Por esa significación, el juego de pelota que realizaban los hombres tuvo un carácter de rito de iniciación, o sea, de paso de una vida profana a una vida sagrada; de adquisición de poderes sobrenaturales que permiten la comunicación con las deidades. Asimismo, tuvo un sentido de rito de regeneración cósmica, por su asociación con el sacrificio por decapitación. Y precisamente por eso, es lógico que el rito fuera realizado por los gobernantes, quienes aparecen en diversos relieves jugando a la pelota.

Varias obras plásticas, como los peraltes del Templo 33 de Yaxchilán (Fig. 11), el marcador de Cancuén y la lápidas del Museo del Indio Americano de Nueva York, muestran a los gobernantes, ataviados con imágenes de los dioses, jugando a la pelota. Los personajes se representaron en el acto mismo de jugar o en actitud pasiva, pero siempre ataviados con los implementos del juego, $y$ sus nombres aparecen en las inscripciones jeroglíficas asociadas.

Así, del mismo modo que los dioses astrales del Popol Vuh logran su apoteosis a través del juego de pelota, los gobernantes del periodo Clásico parecen haber realizado parte de su iniciación como chamanes mediante el rito del juego de pelota. Y además, los gobernantes jugaban por ser ejes del mundo $y$ responsables del orden del cosmos, para propiciar, por magia simpa- tética, la continuidad del movimiento astral, y con él, el de la existencia toda.

Los textos indígenas coloniales corroboran que el juego era practicado por los gobernantes como un ritual. Por ejemplo, el Testamento de los Xpantzay, escrito por los cakchiqueles, asienta que el rey Atunal dijo a sus hermanos: "Hermanos míos, no os dé cuidado, que cuando yo muera entraréis a gobernar. Jugad a la pelota pequeña y a la pelota entre muros entre vosotros". ${ }^{27}$

Todos los ritos que aquí hemos mencionado fueron ritos de poder, en tanto que sacralizaban al gobernante, lo consagraban como eje del cosmos, como sol del mundo social y, principalmente, como responsable de la existencia humana y del universo.

\section{Obras citadas}

Baudez, Claude

1996 "La casa de los cuatro reyes de Balamkú", en Arqueologia Mexicana, vol. III, núm. 18, México, Editorial Raíces, INAH.

Biedermann, Hans

1993 Diccionario de simbolos. Barcelona-Buenos Aires-México, Editorial Paidós.

Champeaux, Gerard de y Dom Sebatien Sterckx

1989 Introducción a los simbolos. Madrid, Ediciones Encuentro.

Chevalier, Jean y Alain Gheerbrant

1991 Diccionario de los simbolos. Barcelona, Editorial Herder.

Códice Porfirio Diaz

1892 Antigüedades Mexicanas publicadas por la Junta Colombina de México en el cuarto centenario del descubrimiento de América. México, Oficinas Tipográficas de la Secretaría de Fomento.

ELIADE, MirCEA

1978-1980 Historia de las creencias y de las ideas religiosas, 4 volúmenes. Madrid, Ediciones Cristiandad.

Garza, Mercedes de LA

1975 El hombre en el pensamiento religioso náhuatl y maya. México, UNAM, IIFL, CEM.

${ }^{27}$ Literatura maya. Compilación y prólogo de Mercedes de la Garza, Biblioteca Ayacucho 57, Barcelona, Editorial Galaxis, 1980 . p. 423.

Estudios de Cultura Maya. Vol. XXII, 2002

Instituto de Investigaciones Filológicas/

Centro de Estudios Mayas, UNAM

ISSN 0185-2574 
$1980 \quad$ Literatura maya. Compilación y prólogo de Mercedes de la Garza. Biblioteca Ayacucho 57, Barcelona, Editorial Galaxis.

1982 El universo sagrado de la serpiente entre los mayas. México, UNAM, IIFL, CEM.

1990 Sueño $y$ alucinación en el mundo náhuatl y maya. México, UNAM, IIFL, CEM.

1997 "Le forze sacre dell'universo Maya", Culture e religioni indigene in America centrale e meridionale, a cargo de Lawrence E. Sullivan, Trattato di Antropologia del Sacro, vol. 6. Milano, Jaca Book-Massimo.

Garza, Mercedes de la y Ana Luisa IzQuierdo

1992 "El juego de los dioses y el juego de los hombres. Simbolismo y carácter ritual del juego de pelota entre los mayas", en El juego de pelota en Mesomérica, raices $y$ supervivencins. México, Siglo XXI Editores.

Grahum, Ian

1977-1997 Corpus of Maya Hieroglyphic Inscriptions. Cambridge, Peabody Museum of Archaeology and Ethnology, Harvard University.

Núnez de la VeGa, Francisco

1988 Constituciones diocesanas del obispado de Chiapa hechas y ordenadas por su señoria ilustrísima el señor maestro don fray Francisco Núñez de la Vega, de la Orden de Predicadores, obispo de Ciudad Real de Chiapa y Soconusco. Edición de María del Carmen León y Mario Humberto Ruz, México, UNAM, IIFL, CEM (Fuentes para el Estudio de la Cultura Maya, 6).

Proskouriakoff, TAtiana

1960 "Historical Implications of a Pattern of Dates at Piedras Negras, Guaremala", en American Antiquity, 25: 454-475.

Popol Vuh. Las antiguas historias del quiché

1968 Traducción de Adrián Recinos, 9a. ed., México, Fondo de Cultura Económica.

SCHele, Linda y Mary MiLler

1986 The Blood of Kings. Dinasty and Ritual in Maya Art. Fort Worth, Tx., Kimbal Art Museum, George Braziller Inc.

SCHele, Linda y DaVid Freidel.

1990 A Forest of Kings. The Untold Story of the Ancient Maya. New York, Quill William Morrow.

Titulo de Otzoyá

1968 en Crespo Morales, Mario, Algunos titulos indigenas del Archivo General del Gobierno de Guatemala. Tesis de licenciatura en Historia, Universidad de San Carlos de Guatemala.

Titulo de Totonicapan

1983 transcripción y traducción de Robert M. Carmack y James L. Mondloch. México, UNAM, IIFL, CEM (Fuentes para el Estudio de la Cultura Maya, 2). 